\title{
Microphone pokes as prank or political action?
}

Challenges to politicians' visibility

in the age of web TV

\author{
Åsa Kroon and Daniel Angus \\ Örebro University / University of Queensland
}

The production of political talk is changing in response to ongoing changes in the overall media ecology. The rise of web TV challenges the previously dominant mediated politics of traditional broadcasting. In this paper we examine the practices of the mediatization of politics in the web TV environment via a humorous encounter between a self-declared "prankster" posing as a web TV broadcaster, and several Swedish politicians. The discussion reflects on various data emanating from this encounter to reveal how Web TV challenges traditional broadcasting norms, and offers fresh challenges for politicians who are continuously adapting to new media logics for exposure.

Keywords: Communicative activity types, interaction, political interviews, prank, tabloids, Web TV

\section{Introduction}

This paper offers a qualitative, explorative inquiry into the production of political talk on the web, examining how web TV productions change the ways in which politics is mediated in relation to traditional broadcasting. Web TV is here used as an umbrella term for live TV productions produced by various media actors, not least the print media. Sweden is very much part of a global trend of newspapers becoming "multiplatform enterprises" (Ju, Jeong and Chyi 2013) which produce extensive online video content, including political news (Negredo 2014). Recent statistics on the media use of Swedes shows that web TV make up $22 \%$ of the population's use of media on digital platforms. In the span of 15-24 year olds, the number is as high as $41 \%$ (Facht 2016). 
The particular interactional web TV form that will be targeted for analysis is what we refer to as "the web TV interview" (Kroon and Eriksson 2016). This is an interview encounter with politicians and journalists that is produced specifically for live streaming on various news sites. What is particular about it in relation to broadcast interviews is that it is conducted by new TV producers such as the tabloid media. It is also not uncommon that it takes place in less orderly, seemingly backstage "messy" settings (ibid). The web TV interview is seen as a relevant target when it comes to displaying how the conditions for political talk change as new TV producers interact with politicians in online productions.

We will address web TV impact on political talk through an, admittedly, rather odd case. A comedy group based in Stockholm called STHLM Panda, known by their followers for their YouTube pranks around town. Two days ahead of the Swedish General Election in 2014, they subjected all of the Swedish party leaders to an interview prank. The prank was not revealed until a YouTube video was released on Election Day. The physical setting where the prank took place was in the lobby of the building of one of the large Swedish broadcasters after a major televised election inquiry, a rather typical space for the tabloid journalists to mingle and film for web TV. In line with Hynes, Sharpe, and Fagan's (2007) and Owen's (2011) respective analyses of the so-called culture jamming movement The Yes Men, we believe that one-time hoaxes like STHLM Panda can enable us to explore issues relating to the political on a broader scale. Here, we use it to showcase what constitutes the new conditions for political talk with the advent of web TV, as well as use it to discuss the action of STHLM Panda and its eventual "political" impact or intent.

Our focus on this specific new form of mediated political talk is interesting as, so far, web TV interviews seem not to be taken very seriously by press secretaries for instance. When asked, a press secretary working for one of the party leaders at the time of the prank wondered "who watches them anyway?" The main consequence for politicians of having to do web TV interviews with tabloids, according to the press secretary, was that there were more media asking for interviews and hence "more microphones in waiting." The web TV interviews were mainly considered to offer instances of quick, improvised talk with a bit of a fun dynamic between interviewer and interviewee while not really allowing time to "talk politics."

In a very broad sense, The STHLM Panda case can be said to display, on a micro level, practices (rather than abstract processes) of the mediatization of politics, where politicians continuously adapt to media logic for exposure (Strömbäck 2008; Strömbäck and Esser 2014), and adopt to the new opportunities and constraints offered by new platforms (Schulz 2014, 57; cf. Hutchby 2001). Also, it connects to the argument that digital media, along with the proliferation of (new) media organizations, make the information environment less controllable and 
creates more fragile positions for elite sources who are dependent on mediated visibility (Thompson 2005). However, these meta-processes and theories provide a backdrop to the case which will be approached from a micro-interactional point of view. In line with a number of other discourse-oriented researchers, we assume that trends in politics and the media can be traced in analyses of concrete mediated interactional instances with a focus on talk and interaction (cf. Ekström and Patrona 2011). This study therefore answers to the call for more political talkoriented micro studies in political communication (Ekström and Tolson 2013).

We begin the paper by defining the differences between broadcast interviews and web interviews, via a discussion of communicative activity types. We then define the Broadcast Talk methodological framework that we use in the later analysis sections to unpack the various web TV interviews of interest to the study. The analysis is then broken into three parts, firstly an analysis of what STHLM Panda present as a fairly standard web TV interview. Secondly, a behind-the-scene video account that reveals the true intensions to "prank" the political interviewees. Lastly, the online comments provided by viewers of this second video are analyzed. Discussion and implications stemming from the analysis are then offered.

\section{Mediated interviews as communicative activity types}

This section provides an overview of the major differences between broadcast interviews and web interviews through the lens of communicative activity types (Linell 2009). It is meant to provide a theoretical understanding of the interactional phenomenon at the heart of the analysis.

Broadcast interviews are familiar mediated social encounters for high-profile politicians, journalists and audiences alike. They are interactions in which politicians perform in relation to "overhearing audiences" (Heritage 1985). Given their long history as a particular form of institutional interaction (Clayman and Heritage 2002) the overall communicative conditions of broadcast interviews are well-known to the participants in them. This makes it easier to plan and predict how to solve communicative tasks, and to know which tasks can, and should be, dealt with in order to fulfill the expected. The accountability interview form is often invoked where politicians are interviewees. In accountability talk, politicians are held accountable to an issue, or a recent event, because of something they themselves have said or done, or something that the institution or party they represent have done (Montgomery 2011, 35). It typically takes place in an institutional environment (studio, press conference) and can be filmed for live airing and/ or be recorded and edited for later broadcasting. Of course, broadcast interviews with politicians can also be less generic and take place in other settings but the 
described variant is recognized as a well-known broadcast interview format. Such an interview can be described as a specific "communicative activity type" (Linell 2009, 201, building on e.g. Goffman 1974, Levinson 1979 and others).

A communicative activity type specifies what kind of communicative situation the participants are involved in (for them and others such as audiences), and shape theirs' and ours' expectations of what is going on, and what the allowable/disallowable contributions are within the encounter. Participants in them are involved in solving communicative problems or tasks on different levels of abstraction (ibid). An overarching project for a politician being interviewed in a communicative activity type defined as a broadcast political interview can, for instance, be to achieve positive visibility in order to come off as worthy of the public's votes. This is partly achieved by locally orienting to the task of answering a question in a competent and knowledgeable manner. Conversely, the interviewer's tasks in accountability may include challenging the politician with tough and critical questions, exposing alleged problems, following the script, amongst other standard practice.

Communicative activity types such as the broadcast political interview described here is not immune to changes but evolves and comes to harbor both residual and emergent interactional norms (Montgomery 2011). The web TV interview such as it materializes in our data is embedded in rather different communicative conditions than broadcast interviews (see also Kroon and Eriksson 2016). As in the case that will presented below, they can take place after a major broadcast event in which the politicians have participated, in a backstage-like area like the lobby of the broadcaster, and be filled with cameras, journalists and media crowding the room. Wodak $(2011,153)$ points out that, "politicians do not merely perform on the publicly visible frontstage represented through the media; but rather they always (italics in original) perform, more or less automatically and intentionally, with mask or without mask." However, it is not unlikely that the politicians in this type of situation experience a more "post-interview mode" than in the prior broadcast performance. Also, the communicative agenda of the tabloid reporters who are there may not always be clear in comparison to an accountability grilling by an experienced broadcast journalist whom the politician know well from prior encounters. The politicians cannot know whether the questions they will be asked will be primarily experiential as one possibly might expect from tabloid (e.g. "how did you think the debate went?"), or accountability-oriented, or both. Given the multiple media which are not established broadcasters that are in the lobby, nor can it be certain as to who the interviewer is going to be, or, for that matter, who the target audience is (Kroon and Eriksson 2016).

As discourse and interaction is always context sensitive, it is fair to say that the altered and "messier" conditions relating to setting, participants and question agenda surrounding the web TV interviews as described above create less distinct 
communicative activity types in which to interact, and the communicative projects nested in them may appear less defined. The more diffuse setting of frontstage/backstage can also impact on the participants' expectations and actions. The messy conditions impact on the kinds of contributions participants will find "/ dis/allowable" (cf. Levinson 1992, 69) in this context. These assumptions will be further picked up for empirical scrutiny in the analysis.

\section{Methodological approach and data}

Although the study's overarching ambition is to address web TV impact on mediated political talk, we approach the question by focusing on the case of The STHLM Panda prank as we see this as illustrative of the overarching inquiry. We therefore unpack the STHLM Panda's YouTube video in its different phases of production and reception.

Generally speaking, this study follows the so-called Broadcast Talk strand of research where forms of talk are treated as fundamental to the way a certain media work (Hutchby 2006; Tolson 2006). What is studied is the involved participants' actions and how these reveal patterns and structures in certain detailed strips of interaction (Tolson 2006). The paper adopts a qualitative approach as an overarching method, but its application has been adapted to the various forms of data it includes. The data, therefore, has been addressed with different levels of detail depending on its purpose to inform the overarching research interest.

First, we look at how STHLM Panda concretely interacts in the web TV context in order to achieve their interviews with the politicians; i.e. what their discursive strategies are to get access among other media. Their activities "reveal" how they understand the communicative space that they are in, and also how the interviewee understands the encounter he is involved in. We also ask how STHLM Panda's interactions are perceived of, and distributed to audiences by other media at the scene. Here, the data is the tabloid Expressen's live airing of a sequence of interviewing by STHLM Panda. In this sequence (presented as Example (1)), we focus on discourse design (STHLM Panda's interview) and on discursive multimodal packaging (Expressen's live material of the interview).

Second, we examine the 2.5 minute YouTube video (Example (2)) released by STHLM Panda where they have re-framed their interviews from two days before. The focus is still on multimodal talk and interaction and the constructed narrative in the video, but with less interactional detail. The interest lies first and foremost on the various discourses that are constructed as these are explicitly and implicitly expressed. The data consists of the released YouTube video on the STHLM Panda channel, published on 14 September, 2014. We also rely on background 
information provided by the STHLM Panda interviewer attained through a Facebook conversation at a later date.

Third, we monitor how the YouTube video is received by the STHLM Panda YouTube users. Approximately 400 comments were broadly categorized in order to capture the users' discursive framing of the video, mainly from the point of what the comments expose when it comes to attitudes to politics, and to politicians. What is the communicative project understood to be from a user perspective? Illustrative examples from the user comment data will inform this part of the analysis.

\section{Analysis}

This section is organized around the three main excerpts of data that were presented in the prior section: (1) Expressen's live streamed video capturing STHLM Panda "in action" while interviewing a politician at the scene of the post-election broadcast mingle with party leaders, (2) STHLM Panda's YouTube video, and (3) YouTube comments to the video.

\subsection{Example 1: Prioritizing Live: Expressen's filming of STHLM Panda}

The first part of Example (1) aims to showcase the importance of live web TV filming, no matter what is shown. The context of Example (1) is an extract from the massive live election web TV coverage aired on Expressen's news site. In this sequence (see Extract (1) below), the tabloid's star reporter Niklas Svensson turns to the camera and introduces the images that are currently displayed to audiences following this live on the web. He begins by stating his own presence; at the same time, his identity as an Expressen reporter is clarified in a caption along with the tabloid's logotype on the screen. He then proceeds to explain what kind of activity is displayed which the viewer also can see:

(1) Well then. Then I'm on camera here at TV4. We're waiting for an interview with the Christian Democrat's party leader Göran Hägglund. He is standing being interviewed by colleagues here. Fredrik Reinfeld he has already left and gone out to meet with the Youth Organizations outside. So any moment now a live interview on Expressen TV with the Christian Democrat's Göran Hägglund

The introduction displays a conversational position in relation to audiences where the reporter, notably, also underscores his own presence on camera although this ought to be rather clear to anyone watching. Several discursive markers orient to 
the nerve of being amidst the political action in "live" mode ("here", "is standing", "any moment now", "live interview"), something which is essential and fundamental to TV's attractiveness generally (Marriott 2007), as it creates a shared moment of suspense and co-presence between broadcaster and viewer (cf. Ellis 2000). He also refers to the activities going on behind him, another interview by "a colleague." After this clarifying fact he turns around towards this on-going exchange. As he does so, the camera zooms in on the interview interaction and a yellow Expressen microphone with the characteristic bee logo appears close to the other interviewing pair to catch what is said. The shot first uses a split screen where, to the left, the viewer can see another party leader being interviewed in another area of the lobby with the talk barely audible. The right hand screen shows The Christian Democrat party leader Göran Hägglund answering questions (Figure 1 below) and soon this is what Expressen exclusively zooms in on.

This short sequence displays the consequences of the non-exclusive live web TV camera which characterizes the web TV context. Interviewers "invade" each other's interactions, seemingly without adhering to any hierarchical norms and principles of who can talk, when, and in which order. It is clear that being "live" is a prioritized mode rather than waiting around until there is a substantial interaction going on. It does not really matter that only the reporter is on camera; the important thing is "being there," or that one listens in on what others are saying or doing. This may create situations where the politician is orienting to one particular interviewer who is asking him questions in a focused interaction (Goffman 1963, 24 ), i.e. an interaction "that occurs when persons gather close together and openly cooperate to sustain a single focus of attention, typically by taking turns," while really being in live mode for another media company. The web context with multiple cameras and lives modes thus constructs a complex participatory framework allowing for "multi-party interaction" (Dynel 2014). Here, the Expressen reporter treats himself (and his audience) as self-evident ratified listeners (whom are not addressed but are entitled to listen in on the other interview), whilst from the politician's point of view, possibly, the journalist occupies the role of unratified listener (someone whom the speaker does not want to communicate any meanings to) (ibid; Bell 1984; Goffman 1981).

So, the broadcast norm of filming orderly, organized exchanges directed by the producer's own interviewee, in which one avoids showing too much dead time, is not adhered to in this context. Also, in this particular instance, the reporter Svensson also displays his own unawareness of who is doing what, as "the colleague" he is referring to, and to which Expressen extends their own microphone to eavesdrop while waiting their turn, is the prankster from STHLM Panda. Extract (2) displays what Expressen's reporter and the viewers now see and hear (see also Figure 1-3 below). 
IR: interviewer, IE: interviewee

(2) IR: Eh, you are still behind in the opinion polls how should you turn this around

IE: Well we have- for one thing I think this debate matters. Tomorrow there comes a new debate on Swedish Television and a new opportunity for the voters to form an opinion and I believe that we gain from showing us together and I also think we gain when they show themselves together

IR: Eh, the voters eh how do you think they think about the opposition now eh

IE: Well /IE is poked on the mouth by mike and reacts by scratching his cheek/ eh what bothers me is that we haven't received any answers I mean for for a long time now they still can't tell us eh who they are and even less what politics they want to stand for. Eh and I believe that the Swedish population want at least what many voters want eh is to know which parties I will get in the bargain so to speak if I vote for one of these three parties. And now the opinion poll situation look looks as if it will take all three parties to outweigh The Alliance and that means that it is The Social Democrats it is the Green Party and it is the old Communist Party and that I think is something that a few voters would like to deliberate upon

IR: Now for the young voters ehm. Now you have thirty seconds to convince the young voters why they should vote for The Alliance and for The Christian Democrats in the election.

IE: Well the most important question concerns the jobs eh we have shown /IR starts raising the microphone/ that we have a politics for jobs for more people jobs for more people that will lead to increased tax revenues and increased tax revenues /IE pulls mike down/ heh means that we can increase support for /IE smiles/ we can increase support for /IE smiles/ elderly care eh this connection is invisible to the Left. For us Christian Democrats family politics is people deciding for themselves and I want to make government in charge of health care in Sweden that I think would improve it.

IR: Thank you!

Discursively speaking, the interview sequence captured in Extract (2) is hardly remarkable. The interviewer is heard to pose three questions to the party leader, none of them particularly conspicuous given the context. Two are "how" questions inviting the politician to expand on what he wants/needs to do to improve his party's standing in the election given recent polls, and to give his opinion on what the voters think of the opposition. The third and final question asks of him 
to elaborate on how to attract young voters. The interviewer may not come across as particularly authoritative as he speaks in a subdued voice with markers of hesitancy (eh, ehm), but he is nonetheless treated as a legitimate interviewer by both the interviewee and by Expressen's reporter calling him "a colleague". This even though the live camera captures both an actual face poke and Hägglund's subsequent scratching of his cheek (Figure 1), as well as the - seemingly uncalled for raising of the microphone way above Hägglund's mouth (Figure 2), causing him to grab it decisively and lowering it while continuing his turn (Figure 3).

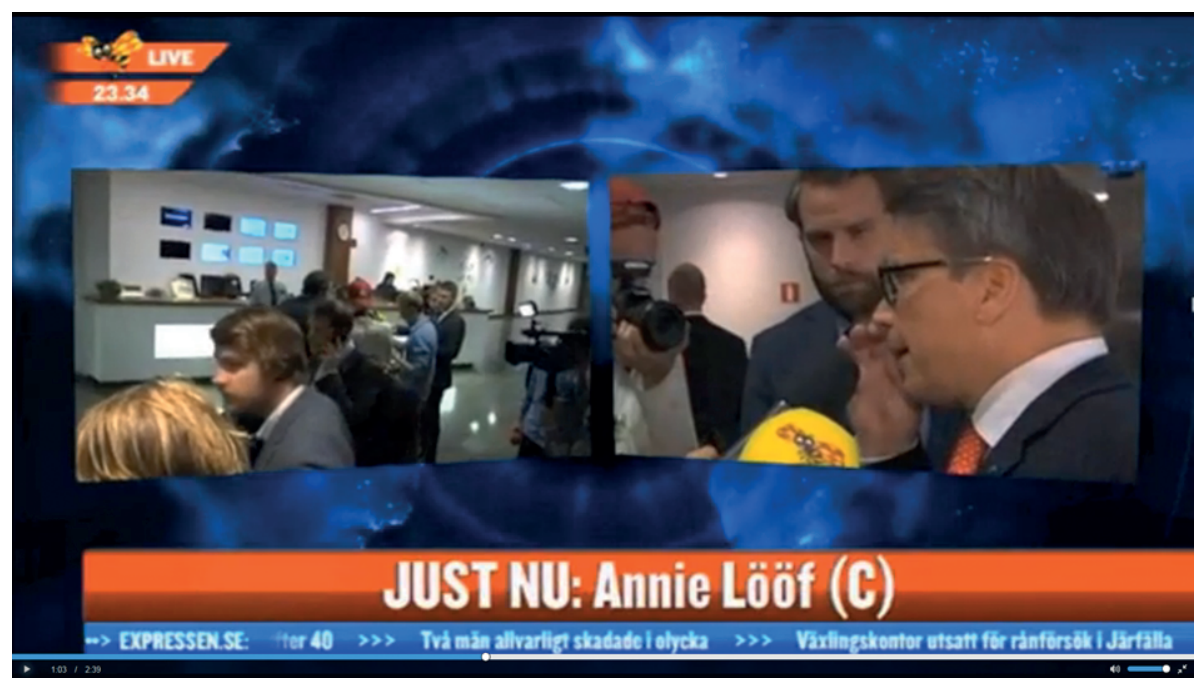

Figure 1. Hägglund's reaction after being poked by the microphone.

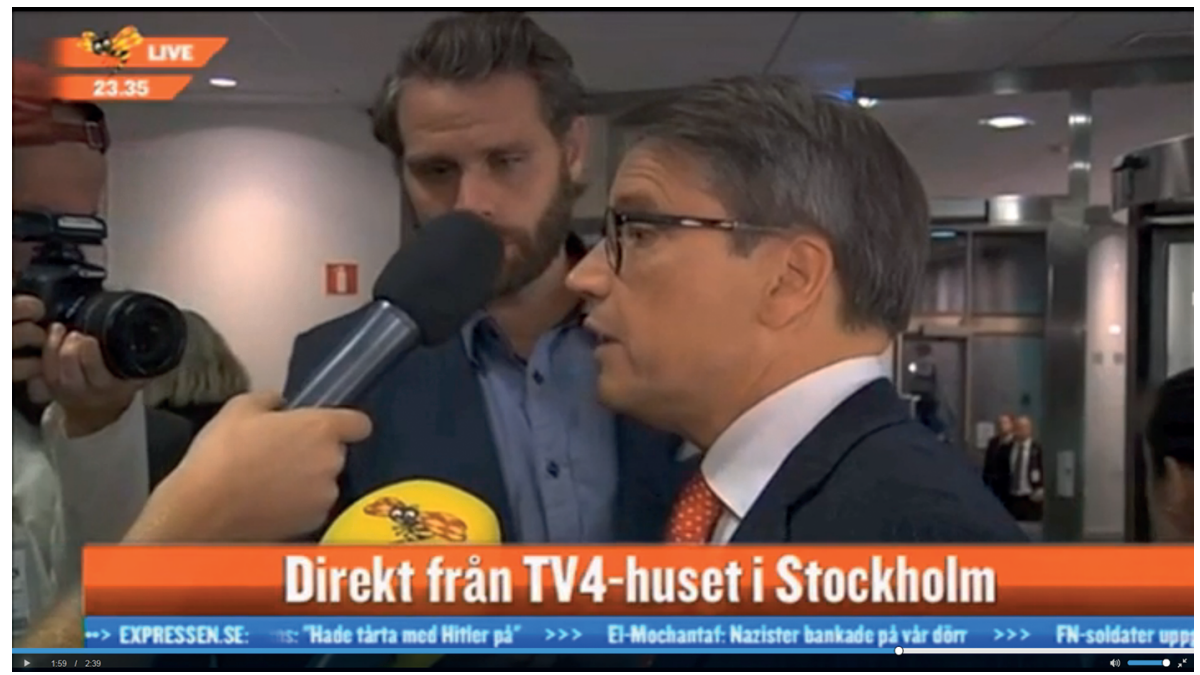

Figure 2. Microphone starting to move upwards during Hägglund's turn. 


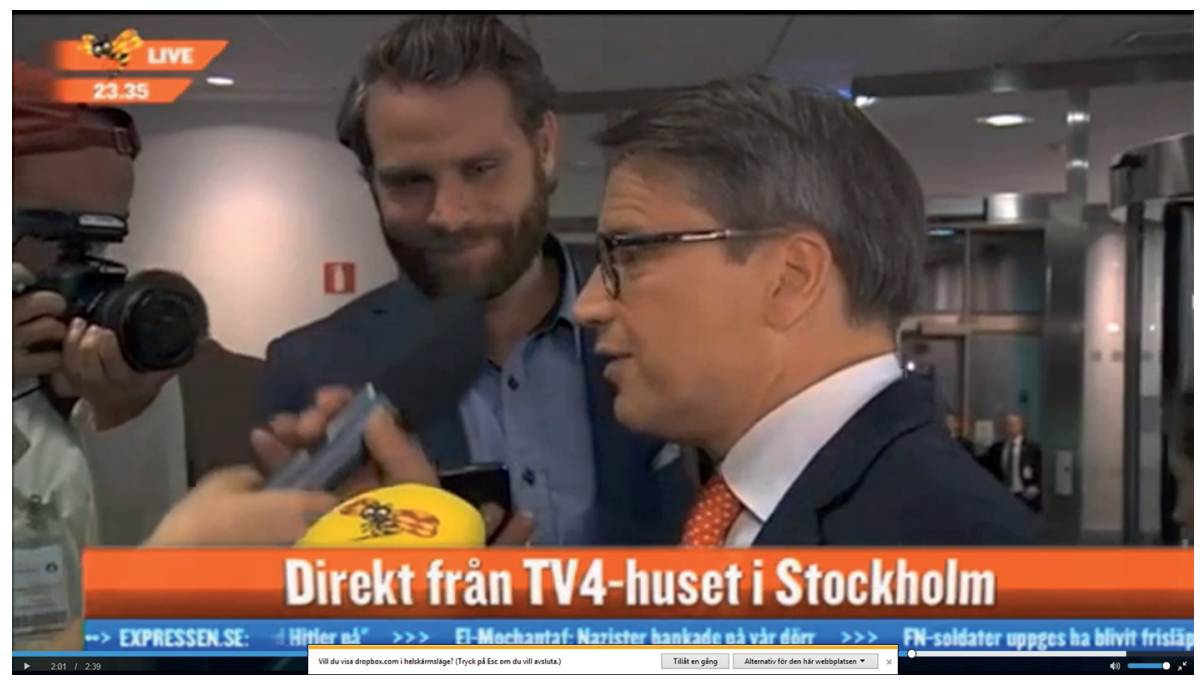

Figure 3. Hägglund grabbing the microphone, pulling it down to an acceptable position.

In their discourse, STHLM Panda adheres to the norms of the interview by asking questions in a relatively orderly manner. That is, they are faithful to the structure and content of a discursive form - the traditional televised interview - in order to achieve authenticity (cf. Owen 2011). What they do not comply with is the nondiscursive norm of not waving the microphone while the party leader delivers his answers. The politician Hägglund has also been the object of a rather prominent poke with the recording device in a prior turn. The press secretary standing alongside Hägglund does nothing to intervene to these odd interview ingredients apart from a slight smile as Hägglund pulls the microphone back down (Figure 3). Despite these being rather offensive activities, no one involved in this interaction, or those capturing it on camera, treats them as disallowable in this context, but stays in frontstage mode. The interviewee accommodates to whatever is happening, and does what he can to restore some kind of normalcy to the situation.

STHLM Panda uses the somewhat disorderly backstage-connoting setting, the multiple and simultaneous interview activities going on, and the fact that unknown media organizations operate alongside well-known ones, as an affordance to achieve a non-discursive mission of poking the politician in the face. This particular communicative project is, however, yet unknown to the participants. Expressen is busy fulfilling its communicative project of delivering live images to audiences while waiting to interview the politician themselves, and the party leader replies to what he thinks are ordinary questions posed on behalf of inquisitive young voters. These quite diverse projects, we argue, are enabled by the general messy conditions in which the web TV interview are embedded. STHLM Panda 
are the only ones in the know in this particular live moment. We now move on to examining the end-result of STHLM Panda's project, their edited You Tube video.
4.2 Example 2: Re-framing the Web TV Interviews - The Panda YouTube video

As was mentioned earlier, a video appears two days after they were originally conducted on STHLM Panda's You Tube channel where they post all their missions, (https://www.youtube.com/watch?v=ouAiIE2rx4U). One sees a smiling man in his 20 's walking along decisively with a grin on his face. He explains that they have gotten hold of press credentials to the final party leader debate ("I can't understand how we got on this press list; it's completely sick that we managed to get on it"). He goes on to say that they are now on their way to interview the party leaders themselves post-debate. (below, Reinfeldt = then Prime Minister):

(3) IR: The plan is that I'm going to go up to the party leaders and then I'm going to $>$ interview them $<$ and $<$ poke a little bit $>$ only like, lightly, with the mic on hhh on on like, Reinfeldt

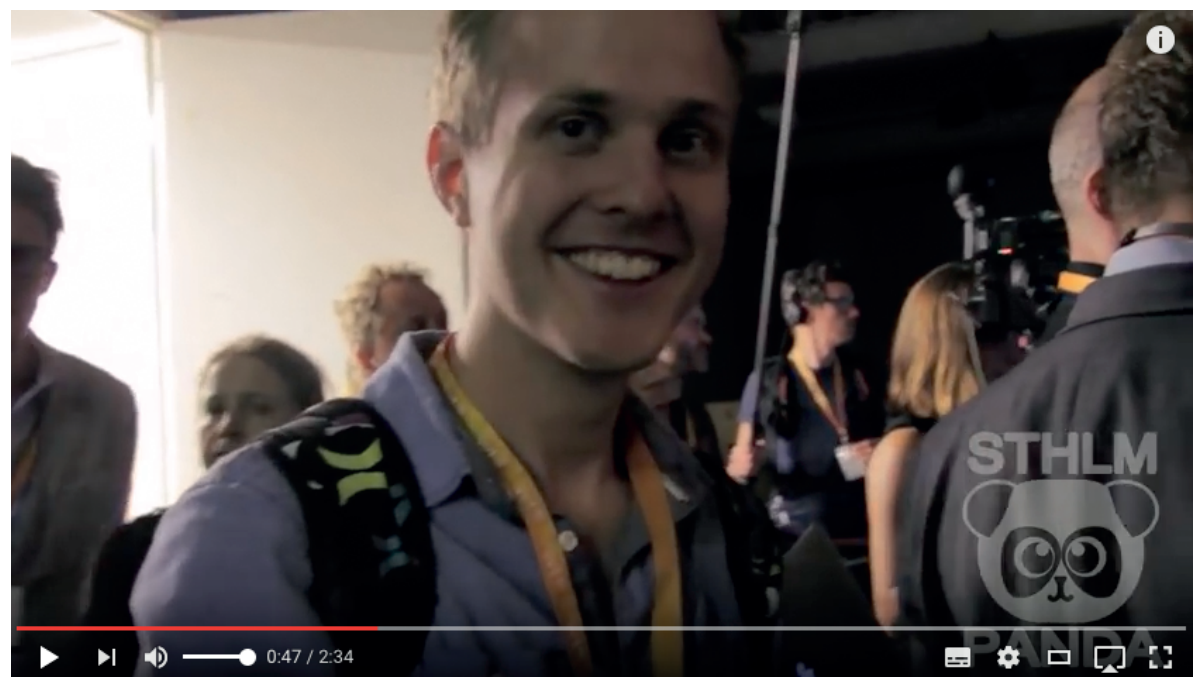

Figure 4. The STHLM Panda interviewer explaining his mission inside the lobby.

The video then goes on to show how the different politicians get poked and also their subsequent reactions. The Sweden Democrat's Jimmie Åkesson tries to keep talking despite several pokes and although the microphone sound goes all blurry as the device is held too close to his mouth. The same seemingly unperturbed behaviour goes for The Left Wing Party's Jonas Sjöstedt who, despite getting 
his cheek bumped on a few occasions, keeps talking without apparent reaction (Figure 5).

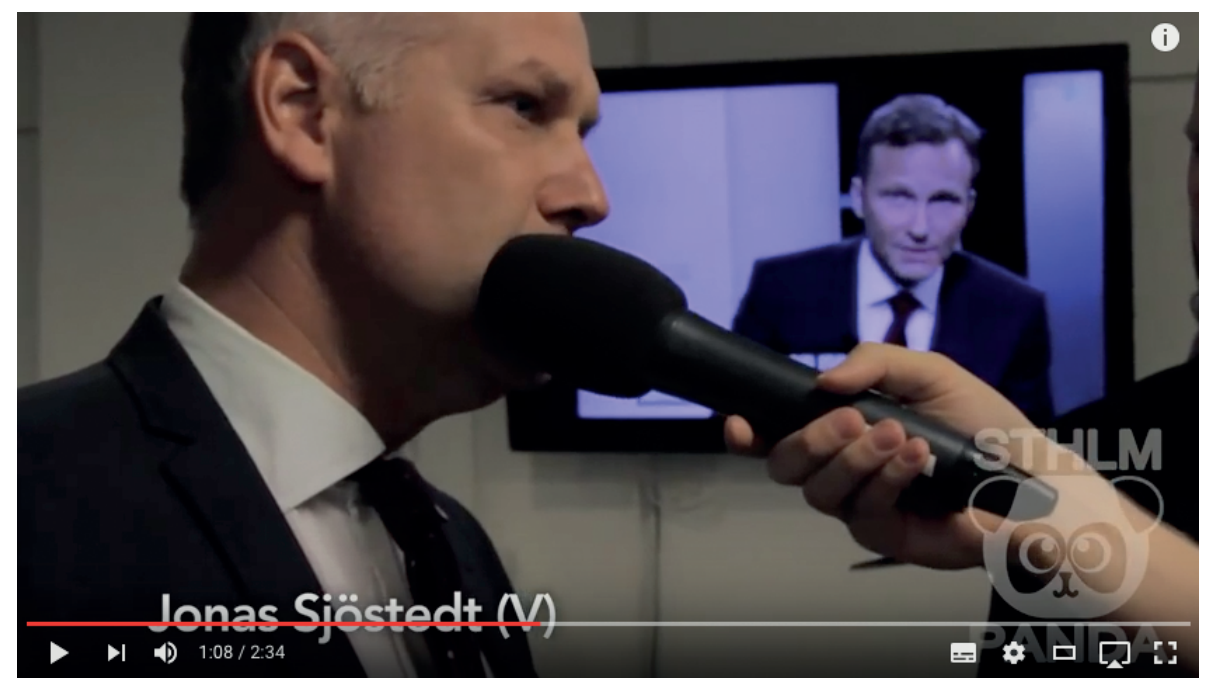

Figure 5. Left Wing Party's Jonas Sjöstedt talking during pokes.

Almost all of the eight party leader's handle the microphone erratic movements and pokes without any dramatic reactions. The only one interrupting the interview is the Center Party's Annie Lööf who receives what looks like a sudden front-teeth poke. She flies backwards while "uff-ing" audibly, but smiling, obviously taken by surprise by the manoeuver. She then pushes the microphone away towards the interviewer and ends the conversation. The video ends with the STHLM Panda interviewer commenting on his successful communicative project, not with a little glee, smiling to the camera off in a calmer section of the lobby (SÄPO being the Swedish Security Police):

(4) IR: No one gets anything. SÄPO gets nothing; they thought it was a mistake all of the time.

The narrative that STHLM Panda constructs in the video highlights first and foremost the joking character of their intended mission. The discursive project of conducting interviews appears merely to be a tool to get to their "real" goal of messing with the microphone. The dominating discourse constructed by the video narrative is, at least seemingly, a humorous one. Similar to The Yes Men (Hynes, Sharpe and Fagan 2007), they use the tactics of "agreeing" their way into a context to gain access to people and places. Unlike that activist group, they do not explicitly use the power gained for any protest or resistance other than towards the security, as in the quote above. Interestingly, though, the STHLM Panda interviewer reveals in 
a written exchange later that indeed they had had a critical ambition that actually overrode the joking one; they had wanted to "on a humorous note show how low security is among our elected politicians." And he concluded:

(5) An achievement I'm very happy to have fulfilled, this time it was a harmless joke but next time it can be someone who gains access with another agenda which can be extremely dangerous as all of our top politicians and the media are all in the same place.

In the video, however, this is communicative project is not fronted. Dynel (2014) develops a framework of interaction for the communicative activities and participatory roles YouTube affords. YouTubers as "recipients," are, apart from (1) interacting in videos themselves as hearers/listeners, conceptualized as (2) recipents watching videos, and (3) addressees and non-addressed ratified listeners (third parties) who read each others comments. Ratified listeners can interchangeably comment and reply to posts, and switch between being explicitly addressed and part of a third party (ibid). The following concerns what Dynel calls interaction on the third level of communication, where YouTubers act as speakers and hearers (most often) prompted by the first level of communication (the video interaction).

\subsection{Example 3: Discourses of Humour, Ridicule, and Rage among Users}

How do users of the STHLM Panda perceive the poke video? The effects or outcomes of political comedy/parody/satire on viewers' opinions and attitudes towards politics and politicians are often claimed to be negative, albeit in different respects (e.g. Balmas 2014; Matthes \& Rauchfleisch 2013). LaMarre et al. (2009) claim that particularly ambiguous comedy material tend to reinforce personally held political beliefs.

At the "neutral" end of the spectrum of commentaries, there are those who simply and straightforwardly accepts STHLM Panda's own main framing of the their project as a mock interview in posts such as lol; die of laughter; hahahaahhah best ever oh jeez I die; the absolutely funniest clip on YouTube; GOD DAMN HOW FUNNY! LAUGHED NON STOP! These users orient to themselves as consumers wanting to be entertained and they express their appreciation of STHLM Panda on their successful mission: Real good job, lads!!!! :D. The fact that the butt of the jokes are party leaders is not explicitly recognized but more implied in the supposed hyperbolic comments by some users. They do not explicitly engage with it as a political text, satirical in nature or otherwise.

The next sub-category of reactions (see the extracts below) can be described as (indirectly) critical towards politics. It is explicitly acknowledged that the 
interviewees are politicians, and that this has a direct implication on the way one appreciates the joke.

(6) Hahaha horribly funny! You de-dramatize politics entirely! Super funny :D Finally politics became funny!

Really funny video. Poke their feet down to earth again.

That was some real nice comments from them $\wedge \wedge$... The politicians are kind of nice anyway if you disregard their views on politics

Hahaha. They didn't care if they were hit by the mike, as long as they were heard :)

The implicit attitudes behind the above statements are that politics is a dramatized and boring practice, and politicians are not in touch with reality, hold unwanted political views, and prioritize talking irrelevant of substance. These users show that they interpret the video not only as purely comedy to which one goes $L O L$, but as a satirical political commentary congruent with their own beliefs and existing attitudes towards politics and politicians. That is, they use the video as a reflection of their own (negatively biased) political preferences as they want to publically recognize them (cf. Boukes et al. 2015).

At the other end of the spectrum, one finds direct critical commentary which address the political dimension and completely ignores the joking discourse which STHLM Panda themselves constructs as being the main one. These types of offensive posts often provoke angry exchanges between users (User 1 - User 2):

(7) U1: You should have shoved the shit into Jimmie Åkesson's mouth so that he choked. Just saying.

U2: Mad?

U1: Mad? No just want him to die ;)

U2: Damn net hater.

Here the supposedly funny video prank becomes a springboard for a heated political positioning where the one holding a certain view of a politician is ridiculed by the other. The joking discourse is completely downplayed and is replaced by a violent and also sexist discourse, the latter one targeting the female party leader who was the only one to cut the interview short.

(8) U1: She started sucking the mike when the camera lights went off U2: Grow up...

Finally, there is an "other" category of comments where STHLM Panda's comic intentions are again downplayed, but where the explicitly invisible security issue is brought to the fore. Comments range from expressing incredulity at having gained this kind of access to fear of potential disasters to come. 
(9) Fun stuff! But how the hell did that happen? In another country you'd have gotten your asses whipped. And ended up in jail, at least.

Yes, only in Sweden would this work. You are the BEST! Doubt it would go through in The White House with like John Kerry.

Users primarily recognize the politicians as a vulnerable group who should be protected from people with less humorous intentions than making a prank. This is in contrast to being seen as laughable targets of an unknowing "roasting" for the benefit of an appreciative audience, or, for that matter, targets of personal derogatory comments. Overall, then, apart from the security-concerned commentators, users tend to treat the You Tube video either as a funny prank, or, as a funny prank that also reveals something (generally negative) about politics and politicians. In both of these instances the politicians' identities as elite sources are trivialized or ignored, as are their political messages that they try to convey in their replies.

\section{Discussion and conclusion}

Firstly, we would like to reflect on STHLM Panda's act in a broader perspective. For them, it was to raise the security issue which was at the heart of their mission, or so they claimed. However, the interviewer did point out that "he was glad that they managed to fool all the party leaders to agree to an interview," in the later correspondence. There are several factors that can be said to point to that STHLM Panda is not as unpolitical as it may seem. There is the choice to not frame it as anything other than a joke which in itself leaves the floor open to (critical) (re) interpretation by users. As mentioned earlier, such ambiguity tends to reinforce personal political attitudes (LaMarre et al. 2009). This is also what happens in many of the user comments following upon the video's publication. There is also the fact that the video is released on Election Day of all days, something which is not lost on users: "This could be one of the election day's most important achievements!" Such comments downgrade the seriousness of an election in a democratic society and upgrade a good laugh at politicians. There is also the effectiveness achieved in the construction of the 2.5 minute video where all eight party leaders are edited together and displayed as struggling with the microphone. They are displayed as a group of funny candid camera people who are oblivious to what they are being subjected to. These ingredients all orient to a strengthened "disgust for politicians" discourse that is prevalent in Western societies. From this perspective, and given how it is actually treated by users, the STHLM Panda prank can be taken as political action dressed in a humorous form whether intended or not; for a joke tends to reveal and affirm the existence of a certain common sense (Hynes, 
Sharpe and Fagan 2007, 115), i.e. here, what we all "know" to be true about politics and politicians.

The other main discourse inherent in the STHLM Panda prank is the implicit criticism towards journalism and the media. It is not one that is articulated by themselves, but it is picked up in the odd user comment: "I would say that this says more about our degenerate journalist staff. Because you appear as blunderheads and amateurs." By equipping themselves with a press accreditation for which they had no professional backing, a camera and a microphone, STHLM Panda managed to access all of the party leaders and "interview them" at such a busy and fragile time as just before the election. The implicit message being that anyone can be a journalist as long as you look like one, and as long as you follow the basic structure of the communicative activity type that everyone thinks you are engaged in. Their act may also be read as a kind of ridiculing of the political interview as such. If anyone can just walk into a lobby and talk to a party leader with any old question two days before the general election, and then put it on YouTube for a laugh; what future does the political interview have as an institutional "elite" genre of news?

Secondly, when it comes to the study's more specific results, it shows that the embedding of web TV interviews in contexts and conditions that are more disorderly allow for a number of divergent communicative projects to go on simultaneously between participants, more so than would be possible in any broadcast interview. So much so that politicians at times have no idea "what is going on". In this particular case, neither politicians nor their press secretaries standing nearby are really aware of what communicative activity type they are involved in. What is believed to be a regular interview with a focus on political matters for live web streaming is really a mock interview in order to edit a YouTube video together. It also shows how web TV interviews "colonize" yet another space, drawing it into full-on frontstage mode.

To sum up, The STHLM Panda prank showcases just how much Swedish politicians have come to accept web TV producers, as well as the "new" media logic which follows from an insatiable, non-exclusive and always live camera. The politicians cannot afford to ignore the web TV formats as they have become so important for mediated visibility, nor can they afford to not adopt to their methods and aesthetics which differ from broadcasting's more orderly productions. In that sense, this development rather seems to strengthen what Strömbäck (2008) has called "the third phase of mediatization" where the media seems to hold the upper hand when it comes to the conditions for how, and where, political talk is produced and represented. However, it would be foolish to think politicians just succumb to media's power without any counter-strategies. In an interview on the Today programme (BBC Radio 4, 14 June 2017), the creator of the British com- 
edy series The Thick of It, Armando Iannucci, reflected on the current political landscape and the media.

(10) We've now got comedians acting as journalists; the roles are flipping. The politicians are the comedians and the comedians are now the interrogators and the journalists. They have the resources of doing forensic analyses of what politicians have actually said.

Future research should surely target what happens as comedy, politics and media merge as, for instance, politicians stand in the House of Commons and deliver one-liners written by hired comedians, while themselves providing "living sketch material" (ibid), and being rewarded with appreciative headlines in the papers the following day.

\section{Funding}

This work was funded by The Swedish Foundation for Humanities and Social Sciences, Project ID: P13-1106:1.

\section{References}

Balmas, Meital. 2014. "When Fake Becomes Real: Combined Exposure to Multiple News Sources and Political Attitudes of Inefficacy, Alienation, and Cynicism." Communication Research 41 (3): 430-454. doi: 10.1177/0093650212453600

Bell, Allan. 1984. "Language Style as Audience Design." In Sociolinguistics: A Reader and Coursebook, ed. by Nikolas Coupland and Adam Jaworski, 240-250. New York: St Mattin's Press Inc.

Boukes, Mark, Hajo G. Boomgaarden, Marjolein Moorman, and Claes H. de Vreese. 2015. "At Odds: Laughing and Thinking? The Appreciation, Processing, and Persuasiveness of Political Satire." Journal of Communication 65 (5): 721-744. doi: 10.1111/jcom.12173

Clayman, Steven, and John Heritage. 2002. The News Interview: Journalists and Public Figures on the Air. Cambridge: Cambridge University Press. doi: 10.1017/CBO9780511613623

Dynel, Marta. 2014. "Participation Framework Underlying YouTube Interaction." Journal of Pragmatics 73: 37-52. doi: 10.1016/j.pragma.2014.04.001

Ellis, John. 2000. Seeing Things: Television in the Age of Uncertainty. London: I.B. Tauris.

Ekström, Mats, and Andrew Tolson. 2013. Media Talk and Political Elections in Europe and America. Hampshire: Palgrave Macmillan. doi: 10.1057/9781137273321

Ekström, Mats, and Marianna Patrona. 2011. Talking Politics in Broadcast Media: Discourse Approaches to Politics, Society and Culture. Amsterdam: John Benjamins Publishing Company. doi: 10.1075/dapsac.42

Facht, Ulrika. 2016. Medie-Sverige 2016 [Media Sweden 2016]. Göteborg: Nordicom. 
Goffman, Erving. 1963. Behaviour in Public Places: Notes on the Social Organization of Gatherings. New York: Free Press.

Goffman, Erving. 1974. Frame Analysis. Cambridge MA: Harvard University Press.

Goffman, Erving. 1981. Forms of Talk. Blackwell: Oxford.

Heritage, John. 1985. "Analyzing News Interviews: Aspects of the Production of Talk for an 'Overhearing' Audience." In Handbook of Discourse Analysis, Vol. 3: Discourse and Dialogue, ed. by Teun A. van Dijk, 95-119. London: Academic Press.

Hutchby, Ian. 2001. Conversation and Technology: From the Telephone to the Internet. Cambridge: Polity Press.

Hutchby, Ian. 2006. Media Talk: Conversation Analysis and the Study of Broadcasting. Maidenhead: Open University Press.

Hynes, Maria, Scott Sharpe, and Bob Fagan. 2007. "Laughing with the Yes Men: the Politics of Affirmation." Continuum: Journal of Media \& Cultural Studies 21 (1): 107-121. doi: 10.1080/10304310601104032

Ju, Alice, Sun Ho Jeong, and Hsiang Iris Chyi. 2013. "Will Social Media Save Newspapers?" Journalism Practice 8 (1): 1-17. doi: 10.1080/17512786.2013.794022

Kroon, Åsa, and Göran Eriksson. 2016. "Messy Interviews: Changing Conditions for Politicians' Visibility on the Web." Media, Culture \& Society 38 (7):1015-1033. doi: $10.1177 / 0163443716635865$

LaMarre, Heather L., Kristen D. Landreville, and Michael A. Beam. 2009. “The Irony of Satire: Political Ideology and the Motivation to See What You Want to See." International Journal of Press/Politics 14 (2): 212-231. doi: 10.1177/1940161208330904

Levinson, Stephen C. 1992/1979. “Activity Types and Language." In Talk at Work: Interaction in Institutional Settings, eds. Paul Drew, and John Heritage, 66-100. Cambridge: Cambridge University Press.

Linell, Per. 2009. Rethinking Language, Mind, and World Dialogically: Interactional and Contextual Theories of Human Sense-making. Charlotte, NC: Information Age Publishing, Inc.

Marriott, Stephanie. 2007. Live Television: Time, Space and the Broadcast Event. London: Sage.

Matthes, Jörg, and Adrian Rauchfleisch. 2013. “The Swiss 'Tina Fey Effect': The Content of Latenight Political Humor and the Negative Effects of Political Parody on the Evaluation of Politicians." Communication Quarterly 61 (5): 596-614. doi: 10.1080/01463373.2013.822405

Montgomery, Martin. 2011. "The Accountability Interview, Politics and Change in UK Public Service Broadcasting." In Talking Politics in Broadcast Media: Discourse Approaches to Politics, Society and Culture, eds. Mats Ekström, and Marianna Patrona, 33-56. Amsterdam: John Benjamins Publishing Company. doi: 10.1075/dapsac.42.06mon

Negredo, Samuel. 2014. "Newspaper Video Content: Genres and Editorial Formats in Spain." View 3 (6): 1-13.

Owen, Louise. 2011. “Identity Correction' The Yes Men and Acts of Discursive 'Leverage"' Performance Research: A Journal of the Performing Arts 16 (2): 28-36. doi: $10.1080 / 13528165.2011 .578726$

Schulz, Winfried. 2014. "Mediatization and New Media." In Mediatization of Politics: Understanding the Transformation of Western Democracies, ed. by Jesper Strömbäck, and Frank Esser, 57-73. Hampshire: Palgrave Macmillan. doi: 10.1057/9781137275844_4

Strömbäck, Jesper. 2008. "Four Phases of Mediatization: An Analysis of the Mediatization of Politics." International Journal of Press/Politics 13 (3): 228-246.

doi: 10.1177/1940161208319097 
Strömbäck, Jesper, and Frank Esser. 2014. "Mediatization of Politics: Towards a Theoretical Framework." In Mediatization of Politics: Understanding the Transformation of Western Democracies, ed. by Jesper Strömbäck, and Frank Esser, 3-28. Hampshire: Palgrave Macmillan. doi: 10.1057/9781137275844_1

Thompson, John B. 2005. “The New Visibility.” Theory, Culture \& Society 22 (6): 31-51. doi: $10.1177 / 0263276405059413$

Tolson, Andrew. 2006. Media Talk: Spoken Discourse on TV and Radio. Edinburgh: Edinburg University Press.

Wodak, Ruth. 2011. The Discourse of Politics in Action: Politics as Usual. Hampshire: Palgrave Macmillan.

Authors' addresses

Åsa Kroon

Department of Humanities, Education and

Social Sciences

Örebro University

SE-701 82 Örebro universitet

Sweden

asa.kroon@oru.se

(D) https://orcid.org/0000-0001-8327-4231

\author{
Daniel Angus \\ School of Communication and Arts / School \\ of Information Technology and Electrical \\ Engineering \\ University of Queensland \\ Brisbane Queensland 4072 \\ Australia \\ d.angus@uq.edu.au
}

\section{Biographical notes}

Åsa Kroon is Professor of Media \& Communication, Örebro University, Sweden. Her research focuses on broadcast talk, interview forms and practices, sports journalism and media technologies.

Daniel Angus is a Senior Lecturer in Computational Social Science, the University of Queensland, Australia. His research focuses on the development of visualization and analysis methods for communication data, with a specific focus on conversation data.

\section{Publication history}

Date received: 30 January 2017

Date accepted: 29 August 2017

Published online: 20 October 2017 